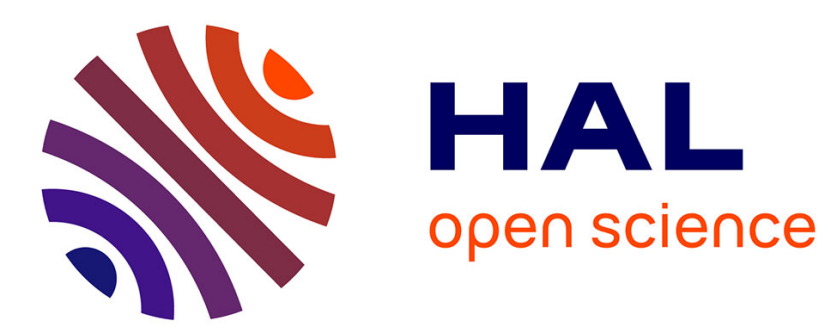

\title{
A Matching Model of the Academic Publication Market
}

Damien Besancenot, Kim Van Huynh, Radu Vranceanu

\section{To cite this version:}

Damien Besancenot, Kim Van Huynh, Radu Vranceanu. A Matching Model of the Academic Publication Market. 2011. halshs-00589186

\section{HAL Id: halshs-00589186 \\ https://shs.hal.science/halshs-00589186}

Preprint submitted on 28 Apr 2011

HAL is a multi-disciplinary open access archive for the deposit and dissemination of scientific research documents, whether they are published or not. The documents may come from teaching and research institutions in France or abroad, or from public or private research centers.
L'archive ouverte pluridisciplinaire HAL, est destinée au dépôt et à la diffusion de documents scientifiques de niveau recherche, publiés ou non, émanant des établissements d'enseignement et de recherche français ou étrangers, des laboratoires publics ou privés. 


\title{
A Matching Model of the Academic Publication Market
}

Forthcoming - Journal of Institutional and Theoretical Economics, 2012

\author{
Damien Besancenot* Kim Huynh $^{\dagger}$ Radu Vranceanu ${ }^{\ddagger}$
}

April 18, 2011

\begin{abstract}
This paper provides a dynamic analysis of the market for academic publications. Given imperfect information about journals' editorial line, authors can sometimes target a wrong journal; in turn, the editor will desk-reject their paper. An equilibrium is defined as a situation where both editors and authors implement their optimal publication strategies, given the matching technology and the prevailing surplus sharing rule. The model can be solved for the equilibrium submission fee, desk rejection rate and ratio between the number of editors and the number of authors.

Keywords: Academic journals, Desk-rejection, Publishing, Matching, Imperfect information.

JEL Classification: C78, A14.
\end{abstract}

\section{Introduction}

Since the very first academic papers were published in 1665, their volume has grown steadily to reach the astronomic figure of 1.3 million papers pear year in 2006 (JinHA [2010]). Experts tend to agree that in the last two decades the number of papers published in all fields of scientific research has increased by an average annual rate of $3 \%$, which is tantamount to a doubling time of 24 years (Jinha [2010], VAn NoORden [2010], Ware [2006]).

As a subset of all scientific publications, social sciences follow the general pattern observed in science. The number of scholars committed to research and the number of submitted papers in social sciences have increased dramatically in the last twenty years. The acceleration of publication efforts was driven

*Corresponding author. University Paris 13 and CEPN, 99 Av. Jean-Baptiste Clément, 93430 Villetaneuse, France. E-mail: besancenot.damien@univ-paris13.fr.

${ }^{\dagger}$ University Paris 2 and LEM, 92 rue D'Assas, 75006 Paris, France. E-mail: kim.besancenot@univ-paris2.fr

${ }^{\ddagger}$ ESSEC Business School and THEMA, 105 Av. Bernard Hirsch, 95021 Cergy, France. E-mail: vranceanu@essec.fr. 
by both the regulatory changes implemented by governments pursuing an activist policy of enhancing research (mainly in Europe, Asia and Australia), and a stronger institutional race for top research positions in the now ubiquitous rankings (Bence and Oppenheim [2004], Groot and Garcia-Valderrama [2006], McGrail, Rickard, and Jones [2006], Frey [2009]). ${ }^{1}$ In turn, this change in volumes brought about several significant changes in the organization of the publication market: firstly, the number of journal titles has also increased, but at a smaller pace than the number of submitted papers, leading to higher congestion. Secondly, while twenty years ago almost no journal charged submission fees, these days submission fees are almost generalized in economics, accounting and finance; they vary from modest amounts, to quite substantial ones. $^{2}$ Thirdly, in the last few years, more and more journals are implementing "desk-rejection procedures", according to which the editor can decide to turn down a paper without sending it to referees, if he considers that the paper does not fit to the aim and scope of the journal (or that the paper is really poorly written). The standard rationale is clearly stated in the Editor Report 2010 of the American Economic Review:

Beginning in January 2006, the Editor and Coeditors have reserved the right to return manuscripts to authors without referee review. The decision to return a manuscript without review is based upon a number of considerations, including expected probability of meeting the standards of the Review, breadth of topic, interest to the AER audience, and other factors. ${ }^{3}$

The aim of this paper is to provide a dynamic analysis of the academic publication market, defined as the place where scholars supply and editors demand academic papers. In general, dynamic models are better fitted to analyze flow markets as compared to stock markets, for which static models provide satisfactory explanations. Indeed, an important characteristic of the academic publication market is the huge flows of papers written, submitted, revised and rejected every year, ultimately leading to a relatively small number of papers published. As compared to a static model of the publication market (e.g.: BESANCENOT AND VRANCEANU [2008]), the dynamic model presents several benefits: first, it can take into account the informational frictions that are a main factor explaining the new phenomenon of desk-rejection; second, it can trace the full history of any paper and thus allows us to study the optimal decision of editors and authors in a genuine intertemporal perspective; third, such a model can account for various stages of one paper (submitted, desk-rejected, referee-rejected, accepted) and describe, if not explain, the transition mechanism from one stage to another.

\footnotetext{
${ }^{1}$ In a representative exemple, the Report of the Editor, January 2, 2010 of the American Economic Review states that the number of submissions to the journal has increased from 641 in 1980 to 1398 in 2009. See: www.aeaweb.org/aer/index.php.

${ }^{2}$ AzAR (2005) reports on submission fees in a sample of important economic journals in 2003. By 2010 the majority of the surveyed journals have raised their fees: see Appendix 1.

${ }^{3}$ See for similar policies the Instructions to Authors web page of Econometrica, Journal of Monetary Economics or the Scandinavian Journal of Economics.
} 
One key assumption is that academic journals are specialized or have their own philosophy. Therefore, a good quality paper, well suited for one journal, might not match the editorial line of another journal. In a world where the number of journal titles in a given field of social sciences counts in hundreds, authors might target the wrong journal. ${ }^{4}$ If a paper does not match the editorial line of journal, it will be desk-rejected; in the opposite case, it will be sent to referees for an assessment of its quality. The traditional refereeing process is then represented in a simplified way, by considering a fixed probability of having a paper accepted for publication. Hence, in this paper we focus on "horizontal" differentiation between identically demanding journals. The quality of the papers is not explicitly brought into the picture; the only assumption we made is that authors of a referee-rejected paper realize that its quality is too low for the going standards and will not send it to another journal. To the contrary, the author of a desk-rejected paper will submit it to another journal, hoping for a better fit.

As an original contribution, we introduce at the editor pre-screening level $a$ matching function that connects the number of successful matches to the total number of submitted papers and the number of journal titles. For sure, in a market with horizontally differentiated journals, the more papers each journal gets, the larger the number of papers fitted for that journal; the larger the number of journals, the deeper their specialization (FREY, EICHENBERGER, AND FREY [2009]), thus the better are chances for an author to target the right journal. ${ }^{5}$ Our approach builds on the classical analysis of the matching process, that has been developed by labor economists. In this field, the matching function between firms and job-seekers, pioneered by PISSARIDES [2000], connects the number of successful matches to the number of unemployed persons and vacant jobs. ${ }^{6}$ A journal in the academic publication market is thus similar to a "large firm" in the labor market framework, given that every journal publishes several papers every period. Thus, the paper-to-journal matching function can be seen as a useful "macroeconomic" device, able to describe in a simple way the informational frictions between authors and editors. In the recent years, the matching model was used to analyze various other flow markets. In a somehow related field, INDERST AND MulLER [2004] have studied the matching equilibrium between inventors who have no resources but produce a constant flow of projects and ideas, with venture capitalists who have the needed resources. The later enter this market as long as they can make positive profits. A standard matching function is used to explain the number of successful pairs formed each period.

\footnotetext{
${ }^{4}$ For instance, the main producer of bibilometric statistics, Thomson ISI Web of Science covers in 2010 about 10000 high impact journals, among which 2100 journals in social science.

${ }^{5}$ This argument has been put forward by Stigler, Stigler, And Friedland [1995] in a different set-up. Taking the perspective of scholars searching for new ideas, they argue that the normal reaction of congestion in publication market is journal specialization; this process should reduce the readers' effort for identifying the relevant journals.

${ }^{6}$ The substantial contribution of Dale Mortensen to this literature should also be acknowledged here (Mortensen [1994], Mortensen and Pissarides [1994]). See also Cahuc And ZYLBERBERG [2004] for a thorough description of the matching approach to labor markets.
} 
In our paper, the long-run equilibrium is defined as a situation where both scholars and editors implement their optimal plans, given the prevailing matching process and surplus sharing rule. The model has three key endogenous variables: the desk-rejection rate, the degree of market openness, defined as the ratio between the number of editors and the number of authors, and the $s u b$ mission fee. After showing that the model presents a single equilibrium, we will analyze how changes in parameters impact the endogenous variables. Some of these parameter changes can be related to policy implemented in the last few years by many higher education institutions in order to strengthen the research productivity of their scholars (McGrail, Rickard, And Jones [2006], Groot and Garcia-Valderrama [2006]). The publication market is decentralized, authors and editors cannot bargain on the surplus allocation. In this paper, the relative shares of total surplus going to editors and respectively authors is taken as given; however, we will be able to determine the Pareto-dominant surplus sharing rule that maximizes the total welfare in this market.

While analyses of the academic publication market belong now to a well established field of research in economics, there are not many theoretical analyses that take into account informational frictions specific to this market. As a related work, we can refer to Besancenot, FARIA, And Huynh [2009] who worked out an equilibrium search model, where authors submit papers and editors search for papers. Editors can be either highly demanding, thus accepting only top papers with a small probability, or tolerant, thus accepting all papers. In equilibrium, authors optimally decide whether to write high or low quality papers. LEE [2009] argues that matching frictions are a key feature of the publication market, enhanced by the rule according to which a paper cannot be submitted to several journals at the same time. He works out a paper allocation model, similar to an equilibrium search model, and analyses the equilibria. Large frictions in the market, leading to higher delays in publication, would support an efficient separating equilibrium where high-quality papers are published by top-tier journals, and lower quality papers are published by second-tier journals. Without providing a formal model, PuJOL [2008] also acknowledges that journals are vertically differentiated, and, due to imperfect information, authors can sometimes target a too high quality journal relatively to their work, thus bearing a high risk of referee-rejection. At difference with these existing studies, in our model journals have identical qualities. This is the price to pay for developing an explicit dynamic analysis of the matching process that is not available elsewhere. If the model were generalized by allowing authors to write either top quality papers or low quality papers, the referee rejection probability could be made endogenous. ${ }^{7}$ Furthermore, editors would specialize, the most demanding rejecting many papers and publishing a small number of top papers (and some lower quality papers) and the others publishing a larger number of lower quality papers (and some top quality papers).

The paper is organized as follows. The next section introduces the main

\footnotetext{
${ }^{7}$ See for such an endogenous screening mechanism, Enger and Gans [1998], Besancenot and Vranceanu [2008] or Heintzelman and Nocetti [2009].
} 
assumption. Section 3 presents the equilibrium and study its main properties. Policy implications are presented in Section 4. We present our conclusions in the last section.

\section{Main assumptions}

\subsection{Authors, papers and editors}

At every period, each author writes one paper, and, following the standard rule in academic publication, he submits it to only one journal. Submissions are uniformly distributed over the existing journals. Each journal is run by one editor. Authors have no perfect information about the editorial line of a journal and therefore can target a wrong journal. Editors must decide whether to have them published or not. The number of editors, denoted by $E$, is given. The number of authors is denoted by $A$ (with $A \geq E$ ). We assume that authors can freely enter or exit this market, depending on their outside opportunities. Hence $A$ can vary (and will be endogenously determined).

We assume that the paper selection mechanism proceeds in two steps. In the first step, the editor must decide whether the paper matches the aim and scope of the journal. If the match is not successful, the editor decides to deskreject the paper. The author will keep on submitting it to other journals until a correct match occurs. If the match is successful, the editor will send it to the referees for an assessment of its quality. A paper sent to referees actually exits the submission process: after the referees deliver their verdict, the paper is either published or withdrawn. We assume that all decisions require a standard time period for processing and analysis.

Hence, in the steady state, the total number of papers submitted for publication each period does not vary. It is made up of the newly written papers (in number $A$ ) and all the papers written at the previous periods that have not yet reached a successful match. Let us denote the steady state number of submissions by $N$ and the probability for a submitted paper to match the editorial line of a journal by $(1-\mu)$; the steady state desk-rejection rate is $\mu$. The steady state number of submitted papers per period is related to the number of new papers by a simple relationship:

$$
N=A \sum_{k=0}^{\infty} \mu^{k}=\frac{A}{1-\mu} .
$$

\subsection{The matching function}

We denote the per-period number of successful matches between authors and editors by $M$. We assume that $M$ can be written as a twice differentiable function with the general form $M=M(E, N)$, with $\partial M(,) / \partial E=M_{E}>0$, and $\partial M(,) / \partial N=M_{N}>0$. The rationale behind these properties is easy to grasp: on the one hand, for a given number of journal titles, the more papers 
are submitted, the more papers per journal and the more of them should fit any of these journals; on the other hand, for a given number of papers, the more journal titles, the greater specialization and the smaller will be chances to target a wrong outlet. Furthermore, this matching function must comply with one important restriction: the number of matches cannot exceed the number of submitted papers: $M(E, N) \leq N$.

In this paper, in order to get an analytical solution, we will assume that the matching function takes the specific form: ${ }^{8}$

$$
\left.M(E, N)=E^{\alpha} N^{1-\alpha} \text { with } \alpha \in\right] 0,1[.
$$

The matching probability $(1-\mu)$ is then:

$$
\begin{aligned}
(1-\mu) & =\frac{M(E, N)}{N}=\left(\frac{E}{N}\right)^{\alpha}=\left(\frac{E}{A}\right)^{\alpha}(1-\mu)^{\alpha} \\
& \Longleftrightarrow(1-\mu)=\left(\frac{E}{A}\right)^{\frac{\alpha}{1-\alpha}} .
\end{aligned}
$$

Equation (3) defines the matching probability by $(1-\mu)=(N / E)^{-\alpha} ; \alpha$ is the opposite of the elasticity of the matching probability with respect to the number of papers per editor. Ceteris paribus, an increase in $\alpha$ brings about a decrease of the matching probability; hence, $\alpha$ can be interpreted as an indirect measure of the informational frictions.

If we denote by $\theta=E / A$ the degree of openness of the academic publication market (a higher $\theta$ being representative of an easier path to publication for an author), with $\theta \in] 0,1$, then the matching probability (Eq. 4) can be written:

$$
1-\mu=\theta^{\frac{\alpha}{1-\alpha}}
$$

Another interesting measure is the number of submissions per journal:

$$
\frac{N}{E}=\frac{A / E}{1-\mu}=\frac{1}{\theta(1-\mu)}=\theta^{-\frac{1}{1-\alpha}}>1 .
$$

\subsection{The expected intertemporal utility of the scholar, $W$}

As already mentioned, at each time period, the scholar writes one paper and submits it for publication to only one journal. Because of informational frictions in the publication market, he will meet an editor interested in his work with probability $(1-\mu)$. When an editor gets a paper in line with the philosophy of the journal, he will send it to external referees for a standard evaluation of the quality of the text. To keep the model as simple as possible, we consider that there are only two possible outcomes of the refereeing process: the paper

\footnotetext{
${ }^{8}$ The model could be numerically solved for any function homogenous of degree one $M(\lambda E, \lambda N)=\lambda M(E, N), \forall \lambda>0$. This property is intuitively appealing: indeed, doubling the number of papers and the number of titles, it is reasonable to assume that the number of matches would double.
} 
can either be referee-rejected with the probability $(1-p)$, or accepted with the probability $p .{ }^{9}$ Denoting by $\beta$ the scholar's discount factor (with $\beta<1$ ), his intertemporal expected utility prior to sending his paper to a journal is:

$$
S=\mu \beta S+(1-\mu)\left\{-s+\beta\left[p W_{A}+(1-p) W_{R}\right]\right\} .
$$

In this expression, the first term is the expected gain if the match was unsuccessful; in this case, that occurs with probability $\mu$, at the next period the scholar will re-submit his paper to another journal and expect the same reward $S$. The second term is the expected payoff if the match is successful (which happens with probability $(1-\mu)$ ): the scholar pays the submission fee $s$ and waits for the editor's decision. The latter takes advice from referees, then either rejects the paper, which worth then $W_{R}$, or accepts it, which worth then $W_{A}$ for its author.

When a paper is referee-rejected, the author must decide if he will try to find another suitable journal for his article. For the sake of parsimony, we will consider here that after a motivated rejection, the paper is definitively withdrawn from the publishing game by its author. Hence, the expected utility of the author of a referee-rejected paper is: $W_{R}=0$.

Many theoretical and empirical analyses have shown that a scholar's pay, promotion and tenure decision depend to a large extent on his publication record (Gomez-Mejia and Balkin [1992], Swidler and Goldreyer [1998], Swanson [2004], Azar [2005]). Hence, we merely assume that the author gets a positive intertemporal utility from publishing one additional paper: $W_{A}=u$, with $u>0 .{ }^{10}$

Then equation (7) can be solved for an explicit value of $S$ :

$$
S=\frac{(1-\mu)(-s+\beta p u)}{1-\mu \beta} .
$$

Denoting the cost of drafting a new paper by $c$, the net expected intertemporal value from writing a paper can be written:

$$
\begin{aligned}
W & =S-c \\
& =\frac{(1-\mu)(-s+\beta p u)}{1-\mu \beta}-c
\end{aligned}
$$

We notice that the problem is meaningful only for $W>0$. The intertemporal utility of the author is a decreasing function in the submission fee $s$.

\subsection{The expected intertemporal utility of the editor, $V$}

At any time period, each editor gets $N / E$ submissions. At a the first stage of the selection process, each paper is screened by the editor. Given the matching

\footnotetext{
${ }^{9}$ The structure of the model would not change if we consider a two stage evaluation process, with a "revise and resubmit" option, followed by accepted or rejected.

${ }^{10}$ Here we assume that the utility from every new publication is constant. PAUL AND RUBIN [1984] argue that, for signaling motives, the value of the first publications should be larger than the value of subsequent ones.
} 
process defined here-above, $M / E$ papers match the aim and scope of the journal and will be sent to referees; the remaining $(N-M) / E$ papers will be desk rejected. The effort of screening one paper involves a cost $g$ for the editor. To keep the paper as simple as possible, we assume that the editor has the same discount factor as the author, $\beta<1$.

Denoting by $V_{D R}$ the expected utility of a desk rejected paper, and by $V_{S}$ the expected utility of a paper sent to the referees, the expected intertemporal payoff of the editor (from being in the publication market) can be written as:

$$
V=-g \frac{N}{E}+\frac{M}{E} V_{S}+\frac{N-M}{E} V_{D R} .
$$

The value of a desk-rejected paper is elementary $V_{D R}=0$. When the editor decides to send the paper to referees, he will charge the author a submission fee $s>0$. At the next period, he will reward the referees with a fee $r \geq 0$ and, according to the referees' reports, he will either accept the paper (and get the payoff $V_{A}$ ) or reject it (and receive $V_{R}$ ). The expected utility $V_{S}$ of a paper sent to the referees can be written:

$$
V_{S}=s+\beta\left[p V_{A}+(1-p) V_{R}-r\right] .
$$

The intertemporal utility of the editor from an accepted paper is $V_{A}=v$ and the intertemporal utility of the author from a referee-rejected paper is $V_{R}=0$. Thus, the expected intertemporal payoff of the editor (Eq.10) becomes:

$$
\begin{aligned}
V & =-g \frac{N}{E}+\frac{M}{E} V_{S} \\
& =\frac{N}{E}\left\{-g+\frac{M}{N}[s+\beta(p v-r)]\right\} \\
& =\frac{N}{E}\{-g+(1-\mu)[s+\beta(p v-r)]\} .
\end{aligned}
$$

where we recall that $(N / E)=\theta^{-1 /(1-\alpha))}$ and $(1-\mu)=\theta^{\alpha /(1-\alpha)}$. The editor's intertemporal surplus is increasing with $s$.

\section{Main relationships and the equilibrium}

\subsection{Author free entry condition and the $s=\Phi(\theta)$ relation- ship}

In general, people who can play the publication game are highly trained individuals who can use their human capital for alternative activities. For instance, in many higher education institutions, faculty members, at some stage of their career, choose to teach more hours in executive education programmes or do administrative work. If the reward from academic publication increases, some of them might be tempted to reduce their teaching or administration hours and do more research (Fox And Milbourne [1999], TAylor, Fender, And 
BuRke [2006]). Consulting or nice jobs in public administration or international organizations are also accessible to many leading scholars (FARIA [2001], [2002])

In our model, these outside opportunities provide the would-be author with a reservation intertemporal utility level, denoted by $\bar{W}$ (with $\bar{W}>0$ ). Under free entry, new authors enter the publication market as long as they expect that the intertemporal gain from this activity is larger than $\bar{W}$, and leave the market in the opposite case. In the steady state equilibrium, the expected intertemporal utility $W$ is driven to $\bar{W}$. The condition $W=\bar{W}$ allows us to write a first relationship between the openness degree, $\theta=E / A$, and the submission fee, $s$. Given the definition of $W$ (Eq. 9), we can write:

$$
\begin{aligned}
W & =\bar{W} \\
& \Leftrightarrow \quad \frac{(1-\mu)\{-s+\beta p u\}}{1-\mu \beta}-c=\bar{W} \\
& \Leftrightarrow s=\beta p u-(\bar{W}+c)\left[(1-\beta) \theta^{-\frac{\alpha}{1-\alpha}}+\beta\right] .
\end{aligned}
$$

Denoting by $\Phi(\theta)=\beta p u-(\bar{W}+c)\left[(1-\beta) \theta^{-\alpha /(1-\alpha)}+\beta\right]$, the last equation can be written in the compact form:

$$
s=\Phi(\theta) .
$$

with $\partial \Phi(\theta) / \partial \theta>0, \partial^{2} \Phi(\theta) / \partial \theta^{2}<0$ and $\lim _{\theta \rightarrow 0} \Phi(\theta)=-\infty, \Phi(1)=\beta p u-$ $(\bar{W}+c)$. Given that $W+c=S$ such as defined by Eq. (8), we can check that $\Phi(1)>0$.

The graph of $\Phi(\theta)$ is plotted in Figure 1:

Recall that authors' intertemporal utility $W$ is decreasing with $s$. All points above the line $s=\Phi(\theta)$ correspond to situations where the intertemporal gain of a scholar is lower than $\bar{W}$, thus scholars are attracted by non academic activities and exit the publication market. The number of authors decreases and $\theta$ increases. In turn, given equation $(5),(1-\mu)$ increases and the probability of desk rejection $\mu$ declines.

Points below the line correspond to an author's intertemporal utility greater than $\bar{W}$, thus some new scholars decide to enter the publication market. Over time the number of authors $A$ increases and the openness degree $\theta=E / A$ decreases .

\subsection{The rent sharing rule and the $s=\Psi(\theta)$ relationship}

In a normally functioning publication market, the representative author obtains the intertemporal utility $W$ from writing a paper and the representative editor gets the intertemporal utility $V$ from running his journal. With $A$ authors and $E$ editors in the market, the overall welfare $\Omega$ generated by the publication market is:

$$
\Omega=E V+A W
$$




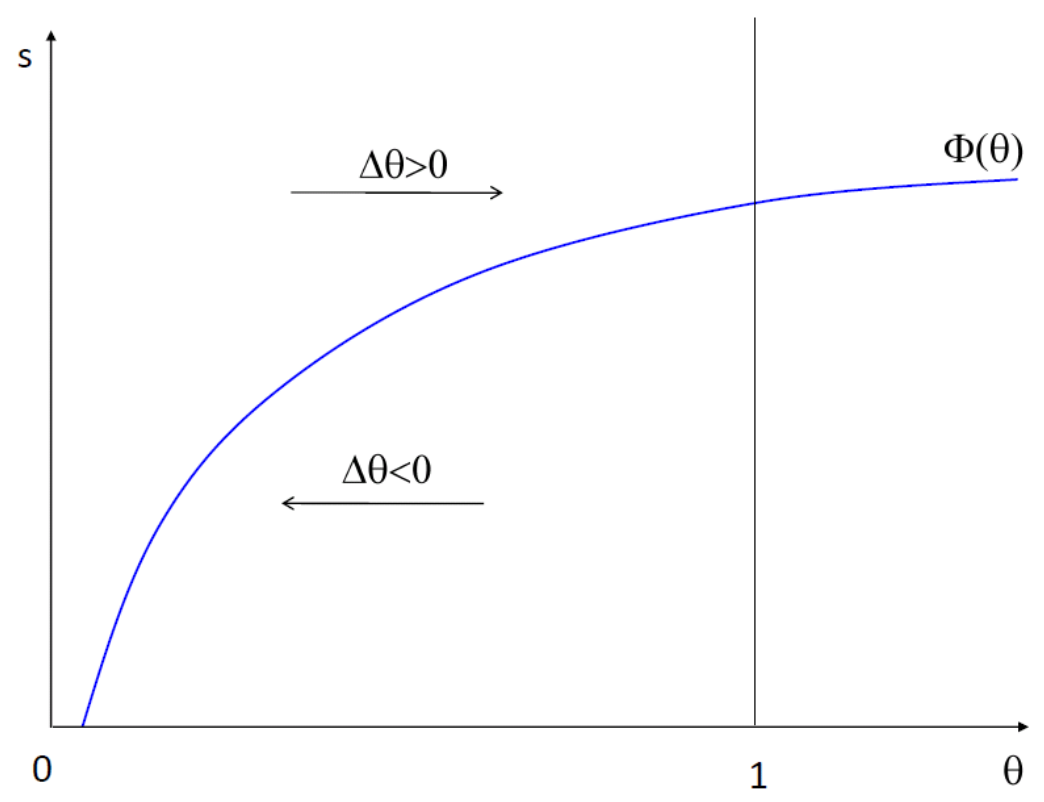

Figure 1: The author free-entry condition

How this total welfare is divided between the two types of players is a matter of social organization of this special market, prevailing institutional arrangements and ultimately the balance of powers between the two groups of players. The market is decentralized, authors and editors cannot bargain on the surplus allocation. In the following we merely assume that editors gets a share $\delta$ of the total surplus while authors gets a share $(1-\delta)$. In other words, we can write that:

$$
E V=\delta \Omega \text { and } A W=(1-\delta) \Omega .
$$

This surplus sharing rule allows us to write:

$$
\frac{E V}{A W}=\frac{\delta}{(1-\delta)} \Longleftrightarrow V=\frac{\delta}{(1-\delta)} \frac{A}{E} W .
$$

But in the long run equilibrium $W=\bar{W}$. Hence, the former equation becomes:

$$
\begin{aligned}
V & =\frac{\delta}{(1-\delta)} \frac{A}{E} \bar{W} \\
& \Longleftrightarrow \frac{N}{E}(-g+(1-\mu)(s+\beta[p v-r]))=\frac{\delta}{(1-\delta)} \frac{A}{E} \bar{W} \\
& \Longleftrightarrow s=\frac{\delta}{(1-\delta)} \bar{W}-\beta[p v-r]+g \theta^{-\frac{\alpha}{1-\alpha}}
\end{aligned}
$$


Denoting by $\Psi(\theta)=\frac{\delta}{(1-\delta)} \bar{W}-\beta[p v-r]+g \theta^{-\alpha /(1-\alpha)}$, the last equation can be written in the compact form:

$$
s=\Psi(\theta),
$$

with $\partial \Psi(\theta) / \partial \theta<0, \partial \Psi^{2}(\theta) / \partial \theta^{2}>0$, and $\lim _{\theta \rightarrow 0} \Psi(\theta)=+\infty, \Psi(1)=\frac{\delta}{(1-\delta)} \bar{W}-$ $\beta[p v-r]+g$.

Figure 2 represents the graph of $\Psi(\theta)$.

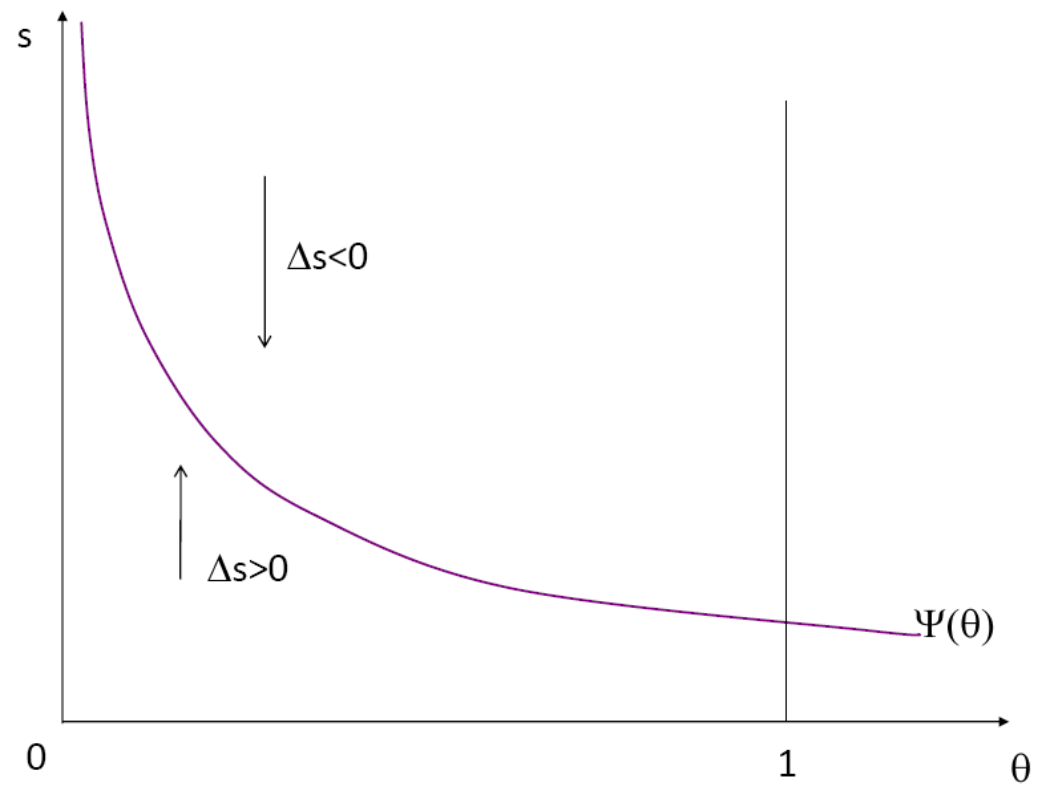

Figure 2: The rent sharing rule

Recall that editors' intertemporal utility $V$ is increasing with $s$. All points below the curve $s=\Psi(\theta)$ represent situations where editors' reward $E V$ is too low relatively to scholars' utility $A W$; to restore the balance, the submission fee is expected to rise. All points above the curve $s=\Psi(\theta)$ correspond to situations where the submission fee must decline to restore the socially agreed balance of welfare shares.

\subsection{The steady state equilibrium}

An equilibrium solution is a pair $(s, \theta)$ with $s>0$ and $\theta \in] 0,1[$ that simultaneously fulfills equations $s=\Phi(\theta)>0$ (the free entry condition, Eq. 14) and $s=\Psi(\theta)>0$ (the surplus sharing condition, Eq. 19). Such an equilibrium is represented as the point $\mathrm{Z}$ in Figure 3. 
The equilibrium degree of openness $\theta$ is implicitly defined by $\Psi(\theta)=\Phi(\theta)$. We can obtain its explicit form:

$$
\begin{aligned}
\Psi(\theta) & =\Phi(\theta) \\
& \Longleftrightarrow \beta p u-(\bar{W}+c)\left[\beta+(1-\beta) \theta^{-\frac{\alpha}{1-\alpha}}\right]=\frac{\delta}{(1-\delta)} \bar{W}-\beta[p v-r]+g \theta^{-\frac{\alpha}{1-\alpha}} \\
& \Longleftrightarrow \theta=\left[\frac{(\bar{W}+c)(1-\beta)+g}{\beta p(u+v)-\beta(r+c)-\left(\beta+\frac{\delta}{1-\delta}\right) \bar{W}}\right]^{\frac{1-\alpha}{\alpha}} .
\end{aligned}
$$

The equilibrium matching probability $(1-\mu)$ results from equation (5):

$$
1-\mu=\theta^{\frac{\alpha}{1-\alpha}}=\frac{(1-\beta)(\bar{W}+c)+g}{\beta p(u+v)-\beta(r+c)-\left(\beta+\frac{\delta}{(1-\delta)}\right) \bar{W}} .
$$

The equilibrium number of submissions per journal (Eq. 6) can also be inferred in a straightforward way:

$$
\frac{N}{E}=\theta^{-\frac{1}{1-\alpha}}=\left[\frac{\beta p(u+v)-\beta(r+c)-\left(\beta+\frac{\delta}{1-\delta}\right) \bar{W}}{(\bar{W}+c)(1-\beta)+g}\right]^{\frac{1}{\alpha}} .
$$

Finally, the equilibrium submission fee is:

$$
\begin{aligned}
s & =\frac{\delta}{(1-\delta)} \bar{W}-\beta[p v-r]+g \theta^{-\frac{\alpha}{1-\alpha}} \\
& \Longleftrightarrow s=\frac{(\bar{W}+c)(1-\beta)\left[\frac{\delta}{(1-\delta)} \bar{W}-\beta(p v-r)\right]+\beta g(p u-c-\bar{W})}{(\bar{W}+c)(1-\beta)+g}(23)
\end{aligned}
$$

A single equilibrium exists under the necessary and sufficient condition:

$$
\begin{aligned}
\Psi(1) & <\Phi(1) \Leftrightarrow \frac{\delta}{(1-\delta)} \bar{W}-\beta[p v-r]+g<\beta p u-(\bar{W}+c) \\
& \Leftrightarrow \frac{1}{(1-\delta)} \bar{W}+\beta r+g+c<\beta p(u+v) .
\end{aligned}
$$

Chances that this condition is fulfilled are better if direct and opportunity cost of each player are relatively small, or if the utility from publishing a paper for either the author or the editor is large enough.

The implicit dynamics represented by the arrows in Figure 3 show that the model presents a Cobweb structure. A sufficient condition for the equilibrium to be locally stable is that the curve $\Phi()$ be steeper than $\Psi()$ (in this case, oscillations dampen around the equilibrium). It turns out that $[d s / d \theta]_{\Phi}>$ $-[d s / d \theta]_{\Psi} \Leftrightarrow(\bar{W}+c)(1-\beta)>g$. Chances to have this condition fulfilled improve if the cost of managing papers by the editor is relatively low, and if authors direct $(c)$ and indirect opportunity cost $(\bar{W})$ of writing papers are large. 


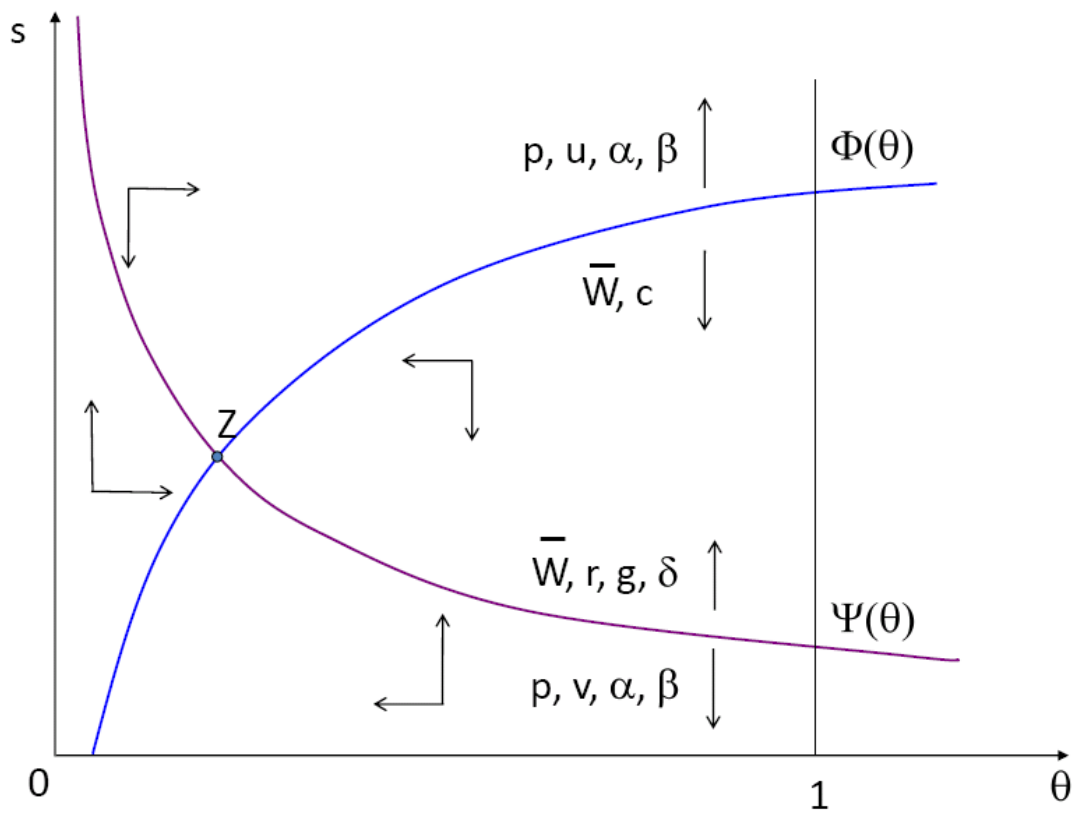

Figure 3: Equilibrium in the academic publication market

\subsection{Properties of the equilibrium}

We can now analyze the impact of changes in the main parameters on the equilibrium values of $s, \theta$ and $\mu$. For so doing, we have to take into account the impact of parameter changes on the two curves, $s=\Phi(\theta)$ and $s=\Psi(\theta)$. Table 1 presents the partial derivatives $\partial \Psi(\theta, i) / \partial i$ and $\partial \Phi(\theta, i) / \partial i$, for $i \in$ $\{r, c, p, v, u, g, \bar{W}, \delta, \alpha, \beta\}$. The signs of these derivatives can be inferred without ambiguity ${ }^{11}$ :

\footnotetext{
${ }^{11}$ Signs of the derivatives with respect to $\beta$ are inferred from a standard participation constraint, if the expected gain is larger than the expected cost, neither the editor nor the author participate to this market. Notice that $1-\theta^{-\alpha /(1-\alpha)}<1$, so $p u>(\bar{W}+c) \Rightarrow p u>$ $(\bar{W}+c)\left[1-\theta^{-\alpha /(1-\alpha)}\right]$.
} 


\begin{tabular}{|l|l|l|}
\hline parameter $i$ & \multicolumn{1}{|l|}{$\partial \Phi(-) / \partial i$} & $\partial \Psi(-) / \partial i$ \\
\hline$r$ & 0 & $\beta$ \\
\hline$c$ & $-\left[(1-\beta) \theta^{-\frac{\alpha}{1-\alpha}}+\beta\right.$ & 0 \\
\hline$p$ & $\beta u$ & $-\beta v$ \\
\hline$v$ & 0 & $-\beta p$ \\
\hline$u$ & $\beta p$ & 0 \\
\hline$g$ & 0 & $\theta^{-\frac{\alpha}{1-\alpha}}$ \\
\hline $\bar{W}$ & $-\left((1-\beta) \theta^{-\frac{\alpha}{1-\alpha}}+\beta\right)$ & $\frac{\delta}{(1-\delta)}$ \\
\hline$\delta$ & 0 & $\frac{1}{(1-\delta)^{2}} W$ \\
\hline$\alpha$ & $\frac{\alpha}{1-\alpha}(\bar{W}+c)(1-\beta) \theta^{-\frac{1}{1-\alpha}}$ & $-\left(\frac{\alpha}{1-\alpha}\right) g \theta^{-\frac{1}{1-\alpha}}$ \\
\hline$\beta$ & $p u-(\bar{W}+c)\left(1-\theta^{-\frac{\alpha}{1-\alpha}}\right)>0$ & $(r-p v)<0$ \\
\hline
\end{tabular}

Table 1. Various partial derivatives

We represent in Figure 3 how the two curves move in response to positive variations of the parameters $\{r, c, p, v, u, g, \bar{W}, \delta, \alpha, \beta\}$ by the respective arrows.

Table 2 indicates the sign of the variation in the equilibrium values of the openness degree $\theta$, the desk-rejection rate $\mu$, and the submission fee $s$, with respect to variations in parameters such as indicated by comparative statics with the two relationships in Figure 3 (or directly from Eq. 20 and Eq. 23).

\begin{tabular}{|c|c|c|c|c|c|c|c|c|c|c|}
\hline & $r$ & $c$ & $p$ & $v$ & $u$ & $g$ & $W$ & $\delta$ & $\alpha$ & $\beta$ \\
\hline$\theta$ & + & + & - & - & - & + & + & + & - & - \\
\hline$\mu$ & - & - & + & + & + & - & - & - & $?$ & + \\
\hline$s$ & + & - & $?$ & - & + & + & $?$ & + & $?$ & $?$ \\
\hline
\end{tabular}

Table 2. Impact of parameter changes on equilibrium values of $\theta, \mu$ and $s$.

\subsection{The Pareto-dominant surplus share}

This sensitivity analysis allows us to address one important issue: what surplus sharing rule brings about the highest total welfare? Such a Pareto-dominant rule would be the outcome of centralized negotiations between authors as a group and editors as a group. In a decentralized market, the share of surplus going to editors $(\delta)$ is the outcome of the relative balance of powers between authors and editors, and is probably different from the social optimal share.

The rent sharing rule (Eq. 16) and the free-entry condition $W=\bar{W}$ allow us to write the total surplus as:

$$
\Omega=\frac{1}{1-\delta} A \bar{W}=[(1-\delta) \theta(\delta)]^{-1} E \bar{W},
$$

where $E$ and $\bar{W}$ are given. The derivative of the total surplus $\Omega$ with respect to $\delta$ is:

$$
\frac{d \Omega}{d \delta}=E \bar{W} \frac{\left[\theta(\delta)-(1-\delta) \theta^{\prime}(\delta)\right]}{[(1-\delta) \theta(\delta)]^{2}} .
$$


The first order condition $\frac{d \Omega}{d \delta}=0$ is equivalent to:

$$
\theta(\delta)=(1-\delta) \theta^{\prime}(\delta)
$$

With the equilibrium degree of openness $\theta$ defined by Eq. (20), after some calculations, we get the optimal share:

$$
\delta^{*}=\frac{\beta[p(u+v)-(r+c)-\bar{W}]-\left(\frac{1-\alpha}{\alpha}\right) \bar{W}}{\beta[p(u+v)-(r+c)+(1-\beta) \bar{W}]} .
$$

In order to make sure that $\delta^{*}$ corresponds to a maximum value of $\Omega$, we can check that for $\delta<\delta^{*}, d \Omega / d \delta>0$, and for $\delta>\delta^{*}, d \Omega / d \delta<0$.

We notice that the optimal share is always smaller than one: $\delta^{*}<1$. In other words, a market organization where editors get the whole surplus cannot be a social optimum.

\section{From theory to policy}

Comparative statics with parameters such as presented in Figure 3 and Table 2 can be related to various structural and institutional changes that occurred in the publication market in the last years. In many regions of the globe (mainly Europe, Asia and Australia), governments are implementing reforms aiming to strengthen ties between academics' compensation and their research performance (Groot and Garcia-Valderrama [2006], McGrail, Rickard, and Jones [2006]). In Europe, substantial momentum to the reform of higher education and R\&D systems was brought by the Lisbon Summit of 2000, where leaders of the EU member countries acknowledged that lasting growth can be achieved only if research performance in these two areas improves in a substantial way. Out of the realm of public regulation, the emergence of ubiquitous rankings of higher education institutions is setting additional pressure on deans to reward research performance more aggressively. ${ }^{12}$ The direct consequence of these institutional changes is an increase in scholars' utility from publishing a paper $(u)$. According to our analysis, when the net utility $u$ of the author from publishing a paper increases, their expected intertemporal gain $W$ goes up. New scholars are thus attracted into the publication market and start submitting papers, the openness degree $\theta=E / A$ declines. The rise in the number of submissions presents an adverse effect on the editors' utility as it brings about an increase in the editors' overall screening cost that is not fully compensated by the bigger number of published papers. To restore the agreed shares of surplus, the submission fees must increase in order to offset the relative decline in editors' surplus $V$. This partially offsets the initial rise in authors' intertemporal gain $W$. In the steady state, at the term of the adjustment process, the submission fee $s$ has increased, the openness degree $\theta$ has decreased and the number of submissions per journal has gone up. These implications of the model are much in

\footnotetext{
${ }^{12}$ See Devinney, Dowling, and Perm-Ajchariyawong [2008] for a survey of business schools rankings.
} 
line with the observed stylized facts. Indeed, as mentioned in the Introduction, in the last few years the number of submitted papers has increased dramatically; many journals are introducing submission fees or push up existing fees.

Subject to an ever growing flow of papers, editors might increase the submission response time just in order to prompt authors to self-select or make higher efforts when choosing their target journal (LEsLie [2005], AzAR [2005], [2006]). In our set-up, an increase in the response time is tantamount to a declining discount factor $\beta$. If the discount factor diminishes, the intertemporal utility of the scholars declines and some of them will leave the market; in turn the openness degree $\theta$ will rise. Since it becomes now more difficult for editors to get papers, their utility $W$ falls as well. The submission fees $s$ might increase or not, depending on the prevailing surplus sharing rule.

The model suggests that some other factors, such as a lower probability of the referees accepting papers, a higher writing cost or an increased editors' power might also offset the rising volume of publications. For instance, ELLISON [2002] argues that over time referees tend to become more demanding. If the probability $p$ of accepting a paper is reduced, both the editors and the scholars can expect a deterioration of their respective surpluses. If some authors leave the publication market, $\theta$ goes up and and the probability of desk rejection declines. At the same time, a smaller number of submissions entails a smaller editorial processing cost. Depending on the relative strength of the two effects (on the one hand, a smaller number of publications per journal pushes down the editor's expected reward, on the other hand, the falling number of submissions brings down the editorial cost), editors would see their surplus raising or not and would adjust submission fees accordingly. In the same line of reasoning, in order to comply with a tougher publishing norm, authors might have to bear larger writing costs $(c)$. This would also push some authors out of the publication market and help containing the raise in submission fees.

In the early years of the publication market, paper publication was mainly driven by a concern of serving the academic community. Indeed, in the early years of the 19th century, most academic journals were published by national and regional associations of scholars. Over time, profit-driven businesses have gradually taken off the academic publication market and market concentration raised over time, to be dominated now by a few major publishing houses (GoEL AND FARIA [2007]). Such institutional change could be responsible for a change in the surplus sharing rule in favour of the editors. If the balance of power between editors and authors changes such as a bigger share of the surplus goes to editors ( $\delta$ goes up), the submission fee must increase. In turn, since $W<\bar{W}$, some scholars leave the publication market, the openness degree $\theta$ will increase and so will do the matching probability $(1-\mu)$. Given that it becomes now easier for authors to have their papers published, that evolution partially offsets the initial increase in fees. At the term of the adjustment process, both $s$ and $\theta$ would have risen.

Finally, note that the editorial strategy of academic journals may also affect the market equilibrium. For instance, in case of a general increase in journals' specialization, it becomes easier for researchers to target the "right" journal 
and informational frictions decrease ( $\alpha$ declines). Desk-rejection should fall, scholars' utility would rise and the publication market would attract more researchers. For a given submission fee $s$, the market openness $\theta$ rises. Editors get and publish more papers, thus their utility edges up as well. The evolution of the submission fees depends on the surplus sharing rule, it might increase or decrease. A higher submission fee might partially offset the direct positive effect on authors' utility.

\section{Conclusion}

For many years now, the flow of papers submitted for publication in academic journals has been increasing steadily. The number of journal titles is also growing, but at smaller pace. The resulting journal congestion is at the origin of substantial frustration and criticism on behalf of both authors and editors. In this context, editors are testing new strategies aimed to preserve the quality of their journals and attract the best contributions. Among these new intriguing policies, one can mention the generalization of (large) submission fees, the lengthier response time to submissions and the implementation of desk-rejection, defined as the possibility for the editor to decide on his own whether a paper matches or not the aim and scope of the journal.

This paper aimed at providing a dynamic model of the academic publication market where scholars supply and journals demand papers. A dynamic model has its own merits, since it can describe in a more thorough way a market characterized by huge flows, such as the market for academic publications. In our model, due to imperfect information, scholars can sometimes target a "wrong" journal in terms of editorial line. The key and original modeling device is a paper-to-journal matching function, relating the number of successful matches to the numbers of authors and journals in the market, inspired from the classical matching model in labor economics (PISSARIDES [2000]). If a paper overcomes this first test, then the editor will send it to referees who ultimately decide whether to publish it or not.

The model presents a single equilibrium, defined as a situation where both editors and authors implement their optimal publishing strategies, given the matching process and the prevailing surplus sharing rule. Parameter changes have in general unambiguous consequences on the main endogenous variables: the ratio between the number of editors and authors (referred to as the openness degree), the number of submissions per editor, the desk rejection rate and the submission fee. In the light of our analysis, the recent trends in the market for publication such as the simultaneous increase in submission fees and number of submissions can be interpreted as a direct consequence of the rise in authors' utility from publishing a paper, itself related to the recent institutional changes in the academic publication market.

One interesting extension allowed us to infer the Pareto-dominant surplus sharing rule, to be reached under a collective bargaining process between the group of authors and the group of editors. In a decentralized market, this 
social optimum would be reached only by chance. Furthermore, our analysis has shown that editors' excessive market power, leading to a very high editor surplus share cannot be the social optimal. The excessive concentration of the publisher market might come with this risk. If the government does not have the information needed to regulate this market, at least it can encourage the emergence of centralized negotiations between associations of authors and editors with respect to submission fees.

Like the elementary version of the labor market matching model, our simple model cannot claim to provide an exhaustive picture of the academic publication market, but can be seen as a good starting point for more powerful analyses, where the introduction of heterogenous agents or a more active role for editors in the paper selection process could bring the model closer to reality. Further research with a calibrated version of this theoretical model including an explicit time dimension would allow to disentangle between the short and the long-run response of the publication market to any reform, thus providing policymakers with a useful tool for policy simulation and evaluation.

\section{References}

[1] Azar, O. H., [2006], "The Academic Review Process: How Can We Make it More Efficient?," The American Economist, 50, 1, pp. 37-50.

[2] Azar, O. H., [2005], "The Review Process in Economics: Is it too Fast?," The Southern Economic Journal, 72, 2, pp. 482-491.

[3] Bence, V. and C. Oppenheim, [2004], "The Influence of Peer Review on the Research Assessment Exercise," Journal of Information Science, 30, 4, pp. $347-368$.

[4] Besancenot, D., J. R. Faria and K. V. Huynh, [2009], "Search and Research: The Influence of the Editorial Board on Journals' Quality," CEPN Working Paper 09-2009.

[5] Besancenot, D. and R. Vranceanu, [2008], "Can Incentives for Research Harm Research? A Business Schools' Tale," The Journal of SocioEconomics, 37, pp. 1248-1265.

[6] Cahuc, P. and A. Zylberberg, [2004], Labor Economics, Cambridge University Press, Cambridge, Mass.

[7] Devinney, Timothy, G. R. Dowling, and N. Perm-Ajchariyawong, [2008], "The Financial Times Business Schools Ranking: What Quality Is this Signal of Quality," European Managment Review, 5, pp. 195-208.

[8] Ellison, G., [2002], "The Slowdown of the Economics Publishing Process," Journal of Political Economy, 110, 5, pp. 947-993. 
[9] Enger, M. And J. S. Gans, [1998], "Why Referees Are not Paid (Enough)," The American Economic Review, 88, 5, pp. 1341-1350.

[10] Faria, J. R., [2002], "Scientific, Business and Political Networks in Academia," Research in Economics, 56, pp. 187-198.

[11] Faria, J. R., [2001], "Rent Seeking in Academia: the Consultancy Disease," The American Economist, 45, 2, pp. 69-73.

[12] Frey, B. S., Eichenberger, R. and R. L. Frey, [2009], "Editorial Ruminations: Publishing Kyklos," Kyklos, 62, 2, pp. 151-160.

[13] Frey, B. S., [2009], "Economists in the PITS," International Review of Economics, 56, 4, pp. 335-346.

[14] Goel, R. K. and J. R. Faria, [2007], "Proliferation of Academic Journals: Effects on Research Quantity and Quality," Metroeconomica, 58, I4, pp. $536-549$.

[15] Gomeiz-Meija, L. R. And D. B. Balkin, [1992], "Determination of Faculty Pay: An Agency Theory Perspective," The Academy of Management Journal, 35, 5, pp. 921-955.

[16] Groot, T. and T. Garcia-Valderrama, [2006], "Research quality and efficiency: An analysis of assessments and management issues in Dutch economics and business research programs," Research Policy, 35, 9, pp. $1362-1376$.

[17] Heintzelman, M. and D. Nocetti, [2009], "Where Should We Submit our Manuscript? An Analysis of Journal Submission Strategies," B.E. Journal of Economic Analysis 83 Policy, 9, 1, (Advances), Article 39.

[18] Inderst, R. And H. M. Muller, [2004], "The Effect of Capital Market Characteristics on the Value of Start-up Firms," The Journal of Financial Economics, 72, 2, pp 319-356.

[19] Jinha, A. F., [2010], "Article 50 Million: An Estimate of the Number of Scholarly Articles in Existence," Learned Publishing, 23, 3, pp. 258-263.

[20] LeE, S.-H., [2009], "A Theory of Self-selection in a Market with Matching Frictions: An Application to Delay in Refereeing Times in Economics Journals," The Journal of Economic Behavior and Organization, 72, 1, pp. $344-360$.

[21] Leslie, D., [2005], "Are Delays in Academic Publishing Necessary?," The American Economic Review, 95, 1, pp. 407-413.

[22] McGrail, M. R., C. M. Rickard and R. Jones, [2006], "Publish or Perish: A Systematic Review of Interventions to Increase Academic Publication Rates," Higher Education Research and Development, 25, 1, pp. 19-35. 
[23] Mortensen, D., [1994], "The Cyclical Behavior of Job and Worker Flows," Journal of Economic Dynamic and Control, 18, pp. 1121-1142.

[24] Mortensen, D. And C. Pissarides, [1994], "Job Creation and Job Destruction in the Theory of Unemployment," Review of Economic Studies, 61, pp. 397-415.

[25] Paul, C. And P. C. Rubin, [1984], "Teaching and Research: The Human Capital Paradigm," Journal of Economic Education, Spring issue, pp. 142147.

[26] Pissarides, C. A. [2000], Equilibrium Unemployment Theory, second edition, Cambridge Mass.

[27] Pujol, F., [2008], "Ranking Journals Following a Matching Model Approach: an Application to Public Economics Journals," Journal of Public Economic Theory, 10, 1, pp. 55-76.

[28] Stigler, G.. J., Stigler, S. M. and C. Friedland, [1995], "The Journals of Economics," Journal of Political Economy, 103,2, pp. 331-359.

[29] Swanson, E. P., [2004], "Publishing in the Majors: a Comparison of Accounting, Finance, Management and Marketing," Contemporary Research in Accounting, 21, 1, pp. 223-255.

[30] Swidler, S. and E. Goldreyer, [1998], "The Value of a Finance Journal Publication", The Journal of Finance, 53, 1, pp. 351-363.

[31] Taylor S. W., Fender, B. F. and K. G. Burke, [2006], "Unravelling the Academic Productivity of Economists: the Opportunity Costs of Teaching and Service," The Southern Economic Journal, 72, 4, pp .846-859.

[32] Ware, M., [2006], Scientific publishing in transition: an overview of current developments. Bristol, Mark Ware Consulting.

[33] Van Noorden, R., [2010], "A Profusion of Measures," Nature, 465, June, pp. $864-866$. 


\section{Appendix1. Submission fees to selected jour- nals, 2003 and 2010}

Data on 2003 were taken by Azar (2005) from the journals' websites. Data on 2010 were taken by authors on journals' websites.

\begin{tabular}{|c|c|c|c|c|}
\hline & \multicolumn{2}{|c|}{$\begin{array}{l}\text { Submission fee } \\
\text { members/subscribers }\end{array}$} & \multicolumn{2}{|c|}{$\begin{array}{l}\text { Submission fee } \\
\text { others }\end{array}$} \\
\hline & 2003 & 2010 & 2003 & 2010 \\
\hline \multicolumn{5}{|l|}{ Economics Journals } \\
\hline AER & $\$ 75$ & $\$ 100$ & $\$ 150$ & $\$ 200$ \\
\hline Econometrica & $\$ 0$ & $\$ 0$ & $\$ 0$ & $\$ 0$ \\
\hline Economica & $\$ 0$ & $\$ 0$ & $\$ 40$ & $\$ 49$ \\
\hline Economic Inquiry & $\$ 100$ & $\$ 120$ & $\$ 160$ & $\$ 180$ \\
\hline Intl. Econ. Review & $\$ 55$ & $\$ 65$ & $\$ 120$ & $\$ 125$ \\
\hline J. Econ. Theory & $\$ 0$ & $\$ 0$ & $\$ 0$ & $\$ 0$ \\
\hline J. Labor Econ. & $\$ 0$ & $\$ 0$ & $\$ 0$ & $\$ 0$ \\
\hline J. Math. Econ. & $\$ 0$ & $\$ 0$ & $\$ 0$ & $\$ 0$ \\
\hline J. Monetary Econ. & $\$ 100$ & $\$ 100$ & $\$ 175$ & $\$ 175$ \\
\hline JPE & $\$ 50$ & $\$ 75$ & $\$ 50$ & $\$ 125$ \\
\hline QJE & $\$ 0$ & $\$ 0$ & $\$ 0$ & $\$ 0$ \\
\hline RAND J. Econ & $\$ 50$ & $\$ 85$ & $\$ 85$ & $\$ 100$ \\
\hline REStat & $\$ 0$ & $\$ 0$ & $\$ 50$ & $\$ 60$ \\
\hline REStud & $\$ 0$ & $\$ 0$ & $\$ 0$ & $\$ 0$ \\
\hline Southern Econ. J. & $\$ 50$ & $\$ 50$ & $\$ 75$ & $\$ 110$ \\
\hline \multicolumn{5}{|l|}{ Accounting Journals } \\
\hline The Accounting Rev. & $\$ 75$ & $\$ 200$ & $\$ 100$ & $\$ 400$ \\
\hline J. Acc. \& Econ. & $\$ 250$ & $\$ 400$ & $\$ 300$ & $\$ 450$ \\
\hline J. Accounting Res. & $\$ 200$ & $\$ 400$ & $\$ 200$ & $\$ 400$ \\
\hline \multicolumn{5}{|l|}{ Finance Journals } \\
\hline J. Finance & $\$ 70$ & $\$ 70$ & $\$ 140$ & $\$ 140$ \\
\hline J. Financial Econ. & $\$ 400$ & $\$ 500$ & $\$ 450$ & $\$ 550$ \\
\hline Rev. Financial Stud. & $\$ 125$ & $\$ 200$ & $\$ 175$ & $\$ 260$ \\
\hline
\end{tabular}

